Fecha de recepción: agosto 2008 Fecha de aceptación: marzo 2009 Versión final: diciembre 2010

\section{Antígona, desde el teatro clásico al Derecho Puro. Perspectivas de la enseñanza a través del método del case-study}

María Laura Pereyra *

\begin{abstract}
Resumen: El presente trabajo tiene como objetivo tomar la teoría del "case - study" y aplicarla de forma original a la enseñanza del Derecho, a través del análisis de la obra de teatro clásico Antigona de Sófocles. Es menester desatacar que son cada vez más frecuentes los factores que nos demuestran que los alumnos encuentran dificultades para superar el abismo que media entre las abstracciones teóricas y las situaciones confusas que se presentan en la realidad. Para cubrir esa carencia formativa el método de estudio de casos es un intento de aprendizaje grupal orientado a extraer el máximo beneficio posible de las experiencias y conocimientos de los otros.

Así Antigona como obra de teatro puede ser relacionada a través de su contenido con el mundo del Derecho buscando generar en el alumno un andamiaje que le permita el manejo inteligente del conocimiento que posee, alejándose así del mero acopio de información.

Por medio del análisis de esta tragedia griega el alumno se encontrará en la encrucijada de dos corrientes filosóficas del Derecho: el Ius Naturalismo o Derecho Natural y el Ius Positivismo o Derecho Positivo. Tal dicotomía le permitirá enfrentarse a dilemas reales que deberá resolver en su vida profesional, por ejemplo qué sucede cuando la Ley prohíbe un acto que el sujeto considera justo y moral, y esa prohibición recae sobre personas amadas.
\end{abstract}

Palabras claves: caso de estudio - derecho natural - derecho positivo - estrategias de enseñanza - objeción de conciencia - teatro clásico.

[Resúmenes en inglés y portugués en la página 36]

"No he nacido para compartir el odio sino el amor"

Antígona

El presente trabajo tiene como objetivo tomar la teoría del case study o "estudio de casos" y aplicarla de forma original a la enseñanza del Derecho, a través del análisis de la obra de teatro clásico Antígona de Sófocles. Es menester desatacar que son cada vez más frecuentes los factores que nos demuestran que los alumnos encuentran dificultades para superar el abismo que media entre las abstracciones teóricas y las situaciones confusas que se presentan en la realidad; para cubrir esa carencia formativa el método de estudio de casos es un intento de aprendizaje grupal orientado a extraer el máximo beneficio posible de las experiencias y conocimientos de los otros.

Así Antígona como obra de teatro puede ser relacionada a través de su contenido con el mundo del Derecho buscando generar en el alumno un andamiaje que le permita el manejo inteligente del co- 
nocimiento que posee, alejándose así del mero acopio de información.

Por medio del análisis de esta tragedia griega el alumno se encontrará en la encrucijada de dos corrientes filosóficas del Derecho el Ius Naturalismo o Derecho Natural y el Ius Positivismo o Derecho Positivo. Tal dicotomía le permitirá enfrentarse a dilemas reales que deberá resolver en su vida profesional, por ejemplo qué sucede cuando la Ley prohíbe un acto que el sujeto considera justo y moral, y esa prohibición recae sobre personas amadas.

\section{Antecedentes}

Antígona es una tragedia griega cuyo autor es Sófocles quien fuera uno de los tres dramaturgos más importantes de la antigua Atenas. Sófocles escribió más de cien piezas dramáticas, de las cuales se conservan siete tragedias completas y fragmentos de otras ochenta o noventa. Las siete obras conservadas son Antígona, Edipo Rey, Electra, Áyax, Las Traquinias, Filóctetes y Edipo en Colona (producida póstumamente en el año 401 a. C.). También se conserva un gran fragmento del drama satírico Los sabuesos, descubierto en un papiro egipcio alrededor del siglo XX. Antígona propone uno de los principales temas del autor: el carácter de los protagonistas, las decisiones que toman y las consecuencias, a menudo dolorosas, de estos dictados de la voluntad personal. La confrontación de la ley divina como agente de lo real y la ley simbólica constituirían el agon fundamental, es decir el conflicto esencial de cuya resolución surge la trama de la tragedia.

\section{Breve resumen de la obra}

La tragedia comienza en el amanecer del día siguiente del final de la guerra, el día en el que los dos hijos de Edipo, Polinices, que ha conducido el ejército de los argivos contra Tebas, y Eteocles, que la ha defendido, se han dado muerte mutuamente. Son las dos hijas de Edipo las que están en escena. Antígona pide a su hermana Ismena que la ayude a enterrar a Polinices, contraviniendo el mandato de Creonte, que ha ordenado que, como castigo al traidor, su cadáver quede insepulto.

La llegada del Coro, formado por ancianos y nobles tebanos, trae el saludo al nuevo día, el día de la victoria y, sobre todo, el día de la paz tras los horrores de la guerra. Los ancianos y nobles han sido llamados por el nuevo gobernante aunque aún no saben la razón. Después hace su aparición Creonte y, antes de anunciar su primera disposición, expresa su confianza en que esos nobles y ancianos tebanos le sirvan a él con la misma fidelidad que ya mostraron. Es entonces cuando el monarca anuncia que prohíbe que se cumpla con el sagrado deber de enterrar a Polinices, el "hermano traidor" y que, en cambio, debe rendírsele homenaje a Eteocles como defensor de la ciudad. El coro es consciente de la gravedad de esa ley, de lo que considera como un atentado contra las leyes religiosas, pero, a fin de cuentas, están sujetos también a esa orden y están convencidos de que nadie sacrificaría su propia vida por contravenirla. Sin embargo, están equivocados. Uno de los soldados encargados de vigilar el cadáver de Polinices llega para anunciar que alguien ha contravenido la ley y ha realizado ritos funerarios en su honor. Más tarde los guardias traen detenida a Antígona porque ha sido ella la que ha violado esas leyes para mantenerse fiel al deber sagrado debido a los muertos. Tras enviarla a una celda, Creonte es incapaz de percibir las consecuencias de su accionar. La entrada de Antígona, camino a su mortal destino, nos la muestra cambiada: ha perdido su altivez y la seguridad inicial. Increpada por Creonte y abandonada por todos, incluso por el Coro, su monólogo de despedida no es un canto de triunfo, sino de tristeza, nostalgia y desolación. Un canto de abandono frente a un deber con el que ha cargado en 
soledad y que no emprende ya con la altivez del triunfo.

La llegada del anciano Tiresias anunciando negros presagios llena a Creonte de inquietud. En un principio se niega a aceptar su error, pero luego su seguridad se desmorona. Creonte intenta evitar que se cumpla la condena de Antígona pero cuando llega adonde se encontraba ésta, observa cómo estaba ahorcada y cómo sujeto a su cintura estaba su hijo Hemón, que había cargado su espada contra él y había muerto. Al volver al palacio con su hijo en brazos, Creonte encuentra que su esposa Eurídice decidió quitarse la vida porque no pudo soportar la muerte de Hemón

La tragedia finalmente termina con las lamentaciones ya tardías e inútiles del tirano Creonte.

\section{El método del estudio de casos - características}

El caso es una herramienta o instrumento para la enseñanza de un tema, en general se han utilizado en forma de ejemplo o problema práctico. Ya la filosofía escolástica medieval utilizaba casos para resolver problemas morales o religiosos. En 1870 C. Columbus Langdell, profesor de la Universidad de Harvard, empezó a enseñar leyes haciendo que los estudiantes leyeran casos en lugar de leer libros de texto. Hacia 1914, el caso se formaliza como método de enseñanza en el programa de Derecho, bajo el término Case System (Wassermann, 1999). La participación en este tipo de técnica busca desarrollar en el alumno habilidades tales como el análisis, síntesis y evaluación de la información. El trabajo con casos posibilita también el desarrollo del pensamiento crítico, el trabajo en equipo y la toma de decisiones, además de otras actitudes y valores como la innovación y la creatividad.

El caso se desarrolla a partir de la selección o construcción de una narración, un relato, que resulte atractivo, de interés para los alumnos. Esa narración expresará un conflicto, un dilema en el que quedará representado un hecho de la realidad, complejo, a partir del cual se centrará la investigación. Un caso, además, permite integrar información proveniente de diferentes campos, por ello es interdisciplinario. Sin embargo debemos tener cuidado con la selección del "caso", puesto que debemos fijarnos como objetivos lograr crear una situación problemática cuya resolución sea compleja puesto que el resultado final debe ser despertar el interés del estudiante, incitar a la discusión, reconocer la controversia y buscar una solución posible que surja de la interacción de la teoría adquirida en aplicación practica.

\section{Perspectiva Jurídica}

Desde siempre ha existido una relación histórica entre el Derecho y la literatura, pues ésta se refiere a aquel permanentemente, unas veces en forma festiva y critica en otras (Parodi, 2002: 243-254). Antígona de esta manera puede servirnos como andamiaje para abordar diversas encrucijadas y discusiones que se dan en el mundo del Derecho.

De esta forma los alumnos podrán descubrir el eterno dilema entre la ley natural y la positiva:

CREONTE: Y aún así ¿̇te atreviste a violar esta ley?

ANTÓGONA: No ha sido Zeus quien ha decretado esta ley ni Diké, compañera de los dioses subterráneos, ha dictada nunca entre los hombres leyes de esta naturaleza. Y no creía yo que tus decretos tuvieran tanta fuerza como para permitir que un hombre solo pueda ser soberano por sobre las leyes no escritas e inmutables de los dioses. Su vigencia no es de hoy ni de ayer sino de siempre, y nadie sabe cuando fue que aparecieron [...]. 
O bien podrán analizar a través de la personalidad de Antigona la definición de objeción de conciencia (Aparisi, 2001) puesto que la protagonista se negó a obedecer las órdenes del rey Creonte por respetar los dictados de su conciencia,

ANTÍGONA: [Es desgracia para mi] si el cadáver de un hijo de mi madre estuviera insepulto y yo lo admitiera, entonces, me sería doloroso. El resto, en cambio, no me es doloroso; y puede que a ti te parezca que he obrado como una insensata, pero, en definitiva, es un insensato a quien rindo cuenta de mi locura.

Como se ve el personaje revindica las leyes divinas con la plena convicción de que está llevando a cabo un acto de justicia, aún a costa de su propia muerte.

Así hay características en esta obra que hacen que sea más atemporal que casi ninguna otra tragedia griega y por lo tanto más actual que nunca: la heroína que se enfrenta, ella sola, contra todo el poder establecido; la lucha de la moral religiosa contra el orden arbitrario, en este caso político o tiránico; la diferencia entre el caso del Rey Creonte, signado por un destino ineludible, y el ejercicio de la libertad individual por Antígona; y por último, la importancia del cumplimiento de los ritos para con los restos de los muertos como bandera de lucha contra la injusticia de su muerte.

\section{Aspectos del método de casos con aplicación practica en Antígona.}

Como hemos descrito en el punto anterior Antígona puede ser analizada desde una variedad de puntos jurídicos. Ahora nos preguntaremos cómo hacer que la lectura de esta obra nos sirva como desencadenante para la resolución de casos reales por parte de los alumnos. Para responder a este interrogante proponemos una guía práctica, que a continuación detallaremos, tomando el análisis de esta tragedia no desde el punto de vista tradicional que separa el Derecho natural del positivo (el cual sin duda es uno de los matices más importantes), sino que utilizaremos uno de lo temas más desarrollados en la actualidad como lo es la "objeción de conciencia". Dicho concepto ha sufrido una evolución y una atención creciente del derecho (Floria, 2004: 25). La objeción de conciencia implica el incumplimiento una obligación de naturaleza jurídica cuya realización produciría en el individuo una agresión grave a la propia conciencia. Lo cierto es que "desde los orígenes del Estado de Derecho se ha entendido que el respeto a la conciencia es uno de los límites más importantes del poder" (Aparisi, 2001) ya que la dignidad y la libertad humana se encuentran por encima del propio Estado. En definitiva la objeción de conciencia se trata de una forma de desobediencia jurídica: supuesta la necesidad de obedecer la ley (no encontramos ahora en los fundamentos de esta obligatoriedad) el objetor la desobedece. La decisión que toma el personaje de Antígona es regirse por la ley divina (no escrita) para oponerse a la ley escrita de la ciudad, generando un conflicto de órdenes: ¿ Hasta donde un ciudadano tiene derecho a revelarse contra su propio Estado?

Una vez delimitado el área temática en la cual aplicaremos el método de "estudio de caso", debemos generar una serie de preguntas criticas que orientarán la reflexión sobre el tema. Dichas preguntas indagarán las cuestiones relevantes de la situación, vincularán las ideas con conocimientos previos, ahondarán la discusión para ponerla en perspectiva con teorías o principios conocidos y favorecerán la búsqueda de soluciones alternativas. Estas preguntas en principio estarán orientadas a la elaboración de la opinión, es por ello que durante esta etapa debemos buscar caracterizar a los personajes y escenarios que aparecen en la tragedia; de esta manera: 
Antígona [se nos presenta] como una imagen [que] no existiría sin su contraparte. Creonte, el rey, que en su soberbia se atreve a retar a los cielos al querer extender su dominio sobre los cadáveres. Recuerda que sólo los dioses tienen mandato sobre los muertos, le increpa Antígona. (Parodi, 2002: 243-254).

En segundo lugar buscaremos preguntas que analicen el caso en concreto: por qué la protagonista decide tomar las leyes no escritas y oponerse al mandato de quien es el monarca y rector de la ciudad; de allí podremos extractar, por ejemplo, las palabras que pronuncia Ismena, hermana de Antígona, y analizarlas:

[..] moriremos si con desprecio de la ley desobedecemos la orden y autoridad del que manda [más aun] yo no busco hacer nada deshonroso, pero me falta fuerzas para obrar contra la voluntad de los ciudadanos.

La tercera fase de este proceso la representa la evaluación y generación de nuevas ideas. Ya hemos definido el rol y postura de cada uno de los personajes, el agon central se encuentra plasmado como el conflicto de dos órdenes, una ley que podemos juzgar injusta y una desobediencia civil, aquí debemos hacer que lo alumnos sean abogados de cada una de las partes. Durante esta etapa mostrarán qué fundamentos toman para apoyar o desechar las posturas contrapuestas, podrán utilizar cualquier clase de herramientas jurídicas desde leyes hasta jurisprudencia del tema.

Por último una vez expuestas por los alumnos ambas posturas el docente generara una réplica de las mismas buscando desestabilizar y haciendo surgir el debate. Por ejemplo, para quienes defiendan la desobediencia civil de Antígona, apoyada en las leyes naturales, se tomará el argumento de que en las lamentaciones finales antes de su muerte este personaje deja entrever que por obedecer los mandatos de su conciencia fue privada de su hogar, linaje, amigos, hermanos y padres, y que cuando invoca a los mismos dioses que ha servido, estos no acuden a sus ruegos. Por otra parte para quienes apoyaron los argumentos de Creonte descubrirán finalmente que él mismo se arrepiente de sus actos:

¡Ay mísero de mí! 'Si, ya lo he aprendido! Sobre mi cabeza, un dios ha dejado caer tan pesada carga. Y por caminos de violencia me ha lanzado, batiendo, aplastando con sus pies lo que era causa de mi alegría. ¡Ay, ay! ¡Esfuerzos y trabajos desgraciados de los hombres!

La lamentación de Creonte anuncia el cambio de posición subjetiva. El monarca solicita finalmente su muerte pero su destino es permanecer con vida y padecer las consecuencias de su soberbia.

\section{Conclusión}

Por medio de este trabajo intentamos tomar una tragedia griega que a pesar de su antigüedad puede fácilmente adaptarse a la enseñanza dentro del aula, en este caso de las ciencias jurídicas. Este hecho lo logramos utilizando la metodología del "estudio de caso" que nos sirve para utilizar la herramientas teóricas que adquieren los alumnos para ponerlas en práctica con el objeto de reflexionar, analizar y discutir en grupos las posibles las salidas que se pueden encontrar a cierto problema. El estudio de caso no ofrece las soluciones al estudiante sino que los entrena para generarlas, los lleva a pensar y a contrastar sus conclusiones con las conclusiones de otros, de esta manera los ejercita en el trabajo cooperativo y a la toma de decisiones en equipo. 
En conclusión el case study lleva al alumno a la generación de alternativas de solución, le permite desarrollar la habilidad creativa, la capacidad de innovación y representa un recurso para conectar la teoría a la práctica real. He ahí su gran valor.

\section{Bibliografía}

Aparisi, Ángela. (2001). “Objeción de Conciencia en la píldora del día siguiente”, Interrogantes.net.

Disponible en: www.interrogantes.net/Angela-Aparisi-Objecion-de-conciencia-en-la-pildora-del-dia-siguiente-PUP180VI001/menu-id-29.html

Floria, Juan Navarro. (2004). El derecho a la objeción de conciencia. Buenos Aires: Ábaco.

Parodi, Ramón Carlos. (2002). El Derecho en el Mercader de Venecia. Ensayos de Derecho procesal. Lima: Huallaga.

Sófocles. (2008). Antígona. Traducción de Sergio Albano. Buenos Aires: Quadrata.

Wassermann, Selma. (1999). El estudio de casos como método de enseñanza. Buenos Aires: Amorrortu.

Summary: The present work proposes to apply the "case-study" theory as a methodology for teaching Law contents, through the analysis of the classic play Antigona by Sófocles. It is necessary to point out that very frequently students find difficulties to surpass the abyss that mediate between the theoretical abstractions and the confused situations that lays in reality. In order to cover that formative deficiency the method of case-study is an attempt of group learning oriented to extract the maximum possible benefit of the experiences and knowledge of the other. Thus Antigona as play can be related through its content to the world of the Law looking for to generate in the student a scaffolding that allows the intelligent handling him of the knowledge that it owns, moving away that the mere storing of information. By means of the analysis of this Greek tragedy the student will be in the crossroads of two philosophical currents of Law: the Ius Naturalism or Natural Law and the Ius Positivism or Positive Law. Such dichotomy will allow him to face real dilemmas that will have to solve in their professional life, for example what happens when the Law prohibits an act that the subject considers moral, and that prohibition falls on loved people.

Key words: case-study - classic theater - consciousness objection - education strategies - natural law - positive law.

Resumo: O presente trabalho toma a teoria do "case - study" para aplicar-a de modo original ao ensino do Direito, através da análise da obra de teatro clássico Antigona de Sófocles. É necessário desatacar que são cada vez mais frequentes os fatores que nos demonstram do que os alunos encontram dificuldades para superar o abismo que medeia entre as abstrações teóricas e as situações confusas que se apresentam na realidade. Para cobrir essa carência formativa o método de estudo de casos é uma tentativa de aprendizagem grupal orientado a extrair o máximo benefício possível das experiências e conhecimentos dos outros. Assim Antigona como obra de teatro pode ser relacionada através de seu conteúdo com o mundo do Direito, procurando gerar no aluno uma preparação para o manejo inteligente do conhecimento que possui, afastando-se assim do mero acopio de informação. Através do análise desta tragédia grega o aluno se encontrará na encruzilhada de duas correntes filosóficas do Direito: o Ius Naturalismo ou Direito Natural e o Ius Positivismo ou Direito Positivo. Tal dicotomia lhe permitirá enfrentar-se a dilemas reais que deverá resolver em sua vida profissional, por exemplo que sucede quando a Lei proíbe um ato que o sujeito considera justo e moral, e essa proibição recai sobre pessoas amadas.

Palavras chave: caso de estudo - direito natural - direito positivo - estratégias de ensino - objeção de consciência - teatro clássico.

${ }^{*}$ Abogada (UBA). Docente en la Facultad de Derecho (UBA). Miembro del Equipo docente de la materia Introducción a la Investigación, Facultad de Diseño y Comunicación de la UP. Redactora e investigadora. 